\title{
Clinical Decision Support and Optional Point of Care Testing of Renal Function for Safe Use of Antibiotics in Elderly Patients: A Retrospective Study in Community Pharmacy Practice
}

\author{
Mette Heringa ${ }^{1,2,3}$ (D) Annemieke Floor-Schreudering ${ }^{1,2} \cdot$ Peter A. G. M. De Smet $^{4} \cdot$ \\ Marcel L. Bouvy ${ }^{1,2}$
}

Published online: 8 November 2017

(c) The Author(s) 2017. This article is an open access publication

\begin{abstract}
Objective The aim was to investigate the management of drug therapy alerts on safe use of antibiotics in elderly patients with (potential) renal impairment and the contribution of optional creatinine point of care testing (PoCT) in community pharmacy practice.

Methods Community pharmacists used a clinical decision support system (CDSS) for seven antibiotics. Alerts were generated during prescription processing in the case of previously registered renal impairment and when no information on renal function was available for patients aged 70 and over. Pharmacists could perform PoCT when renal function could not be retrieved from other health care professionals. Actions were registered in the CDSS. A retrospective descriptive analysis of alert management, performed PoCT and medication dispensing histories was performed.

Results A total of 351 pharmacists registered the management of 88,391 alerts for 64,763 patients. For 68,721 alerts $(77.7 \%)$, the pharmacist retrieved a renal function above the threshold for intervention. $1.7 \%$ of the alerts $(n=1532)$ led to a prescription modification because of renal impairment; in $3.0 \%$ of the alerts $(n=2631)$, the
\end{abstract}

Mette Heringa

m.heringa@sirstevenshof.nl

1 SIR Institute for Pharmacy Practice and Policy, Theda Mansholtstraat 5B, $2331 \mathrm{JE}$ Leiden, The Netherlands

2 Division of Pharmacoepidemiology and Clinical Pharmacology, Utrecht Institute for Pharmaceutical Sciences, Utrecht University, Utrecht, The Netherlands

3 Health Base Foundation, Houten, The Netherlands

4 Departments of Clinical Pharmacy and IQ Healthcare, University Medical Centre St Radboud, Nijmegen, The Netherlands patient had renal impairment, but the pharmacist judged that no intervention was needed. Pharmacists performed 1988 PoCTs (2.2\% of the alerts), which led to 15 prescription modifications ( $0.8 \%$ of the PoCT).

Conclusion Community pharmacists performed CDSSbased interventions to prevent potentially inappropriate (dosing of) antibiotics in elderly patients with renal impairment. Pharmacists were well able to retrieve information on renal function, using PoCT in a limited number of cases. The intervention rate could be greatly increased by better registration of information on renal function. Performing PoCT seems especially worthwhile in the highest age groups.

\section{Key Points}

Community pharmacists can use clinical decision support to detect both inappropriate drug use in renal impairment and a lack of data on renal function.

The efficiency of clinical decision support in community pharmacies could be increased by better registration of information on renal function.

In the case of urgency, creatinine point of care testing by community pharmacists could be of added value, especially for older patients.

\section{Introduction}

Renal impairment is common, with chronic kidney disease affecting up to $10 \%$ of the population and over $25 \%$ of the elderly [1-3]. Impaired renal function has been shown to be an important risk factor for medication-related hospital admissions [4, 5]. Drug elimination can be reduced in the 
case of renal impairment, which can result in drug accumulation and toxicity. Moreover, reduced renal elimination may decrease the effectiveness of drugs acting in the urine (for example, nitrofurantoin) [6]. Therefore, some drugs should be avoided in renal impairment, and for other drugs, the dosage should be adjusted according to the patient's renal function.

Clinical decision support systems (CDSSs) can help to prevent several types of drug therapy-related problems $[7,8]$. Health care professionals have successfully used CDSSs to detect potentially inappropriate drug use in patients with known impaired renal function [9-12]. Moreover, CDSSs can be used to detect situations in which information on patients' renal function is lacking while this information is needed for safe drug use.

Pharmacists can contribute to safe drug use in patients with renal impairment by checking whether the prescribed dose has been adequately adjusted to the renal function. It has been shown that CDSS-based interventions by community pharmacists can reduce the number of drug therapy-related problems with regard to renal impairment [13-15]. Therefore, it is important that information on patients' renal function is available in community pharmacy. Investigations in the Netherlands showed that this information is often incomplete [16-18]. When information on renal function cannot be obtained (from, for example, the physician), but is urgently needed, point of care testing (PoCT) may be an alternative to estimate renal function. It has been shown on a small scale that PoCT of creatinine is applicable in community pharmacies [19].

An urgent need for information on renal function could inter alia be expected in the case of prescriptions for antibiotics, as an immediate start of the drug is generally needed. Several commonly used antibiotics are renally excreted and need dose adjustment in the case of renal impairment. Although PoCT in community pharmacies has been investigated, as well as several kinds of CDSSs, the combination has not yet been implemented on a large scale.

We aimed to investigate the management of drug therapy alerts on safe use of antibiotics in elderly patients with (potential) renal impairment and the contribution of optional PoCT of renal function in daily community pharmacy practice.

\section{Methods}

\subsection{Setting}

Clinical decision support rules on antibiotic use in renal impairment and PoCT for creatinine were implemented in 351 community pharmacies between June 2015 and August 2016. The participating pharmacies were franchisees of
Service Apotheek and were distributed over the Netherlands in both rural and urban areas. These pharmacists routinely used a web-based CDSS in addition to their pharmacy information system. Patients' medication dispensing history, age and gender were automatically available in the CDSS. Renal function had to be registered manually. The CDSS could generate pop-up alerts during the prescription processing in the pharmacy information system. All pharmacists were trained in performing PoCT, interpretation of renal function measures, and registration in the CDSS by attending 3 half-day meetings (before start, after 3 months and after 6 months) and by e-learning.

\subsection{Clinical Decision Support Rules}

Seven clinical decision support rules were implemented for amoxicillin + clavulanic acid, ciprofloxacin, clarithromycin, co-trimoxazole, nitrofurantoin, norfloxacin, and trimethoprim. Alerts were triggered by the CDSS for patients with a documented estimated glomerular filtration rate (eGFR) of $\leq 30 \mathrm{ml} / \mathrm{min} / 1.73 \mathrm{~m}^{2}$, for patients with an outdated eGFR (measured $>56$ weeks ago), and for patients aged 70 years and older for whom no eGFR had been registered in the CDSS. For the algorithm of the clinical decision rule, see Fig. 1. When an alert was triggered, a drug-specific advice for dose adjustment in the case of an eGFR of $\leq 30 \mathrm{ml} / \mathrm{min} /$ $1.73 \mathrm{~m}^{2}$ was displayed (except for nitrofurantoin, where replacement of the drug was advised). Based on the advice, pharmacists had to check the dose manually and adjust it when needed, after consultation with the prescriber. The displayed advices were in accordance with the Dutch national guidelines on drug dosing in renal impairment [20]; differences with international guidelines exist, comparable to the differences between several international guidelines [21]. The Dutch national guidelines are widely accepted by physicians and pharmacists.

\subsection{PoCT for Creatinine}

Pharmacists had the possibility to use the Menarini Statsensor Creatinine Xpress-meter for PoCT with capillary puncture. With this meter, blood creatinine level can be measured within $1 \mathrm{~min}$, with sufficient accuracy to detect renal impairment in adults [22]. In the study, PoCT was intended for situations where information on renal function was urgently needed and not available from other sources [e.g., the general practitioner (GP)]. Pharmacists were trained on estimating the GFR based on the creatinine measurement basically using the Modification of Diet in Renal Disease (MDRD) formula [23], and using the Cockcroft and Gault equation for creatinine clearance [24] where appropriate $\}$. Calculations of eGFR were performed similarly as performed by laboratories in both primary and 


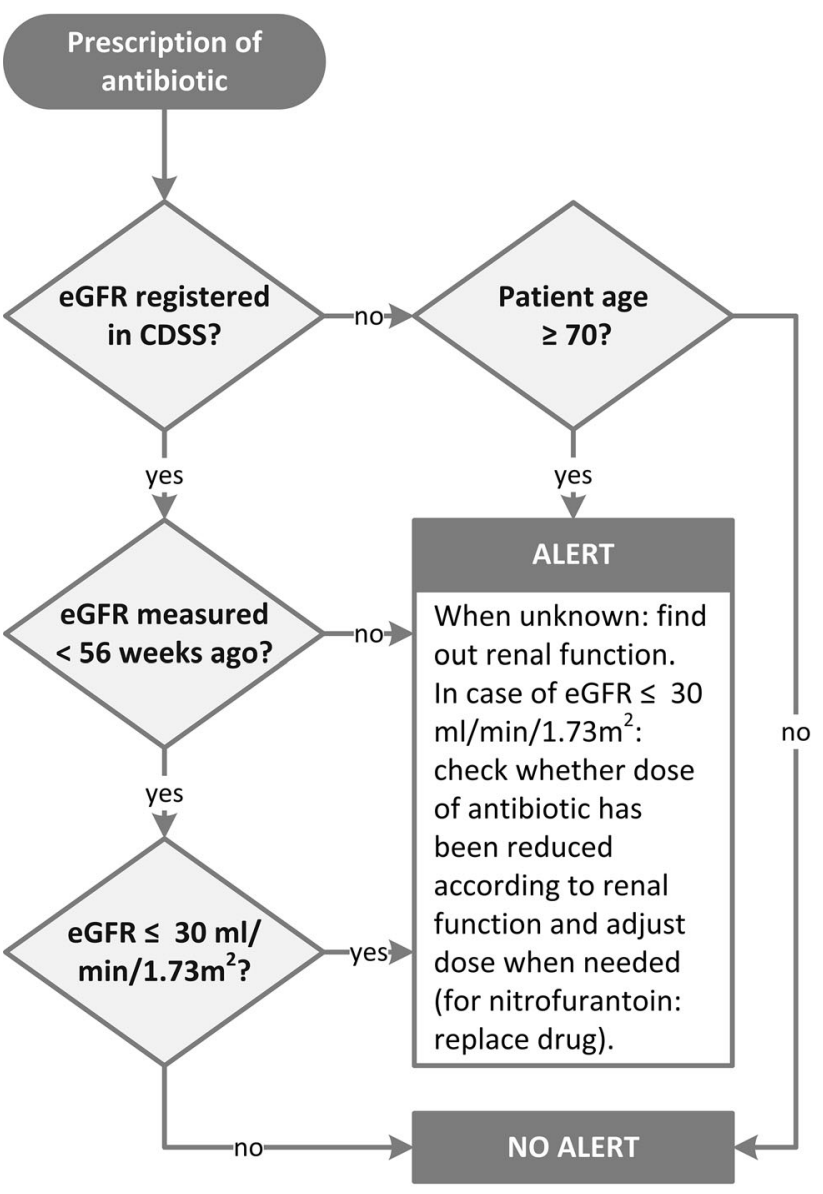

CDSS = clinical decision support system;

eGFR = estimated glomerular filtration rate

Fig. 1 Algorithm of clinical decision support rule for antibiotics and renal function. CDSS clinical decision support system, eGFR estimated glomerular filtration rate

secondary care in the Netherlands. On a local level, pharmacists made arrangements with GPs about the exchange of information on renal function, the use of PoCT and the follow-up after a PoCT measurement. Protocols and leaflets to inform both GPs and patients about PoCT were provided to the participating pharmacists.

\subsection{Data Collection and Analysis}

The pharmacists registered the alert management in the CDSS according to predefined options regarding the situation and intervention; additional free text could be entered. Data from the CDSS were registered in a central database. Anonymized data were extracted from this database for all alerts, including alert management, medication dispensing history for the 4 months preceding the alert fincluding dosing regimen and anatomical therapeutic chemical classification (ATC) [25]\}, and registered data on renal function.
A descriptive analysis was performed using Microsoft Access and SPSS (version 20.0; SPSS Inc. Chicago, IL, USA). The data were checked for completeness and consistency with regard to the combination of the registered alert management, dispensed medicine, and renal function. Data registration was considered incomplete when information in one of the data fields was lacking while the other data fields suggested that the pharmacist had the information available. Data registration was considered inconsistent when the information in the different data fields was not matching. For examples of the data check, see Table 1 . In this study, an eGFR of $\leq 50 \mathrm{ml} / \mathrm{min} / 1.73 \mathrm{~m}^{2}$ was considered as impaired renal function and $\leq 30 \mathrm{ml} / \mathrm{min} /$ $1.73 \mathrm{~m}^{2}$ as severely impaired renal function. These thresholds were derived from categories used in the Dutch guidelines on drug dosing in renal impairment [20], which are based on the 2004 European Medicines Agency guideline [26]. Consistent with the dosing advices, the threshold of 50 is, in the Netherlands, often used for informing pharmacists on impaired renal function; it indicates a need for closer monitoring of renal function and of current and future drug use.

\subsection{Ethics and Confidentiality}

As this was a retrospective, anonymized database analysis, the study was exempt from ethical review. To protect patients' and pharmacists' privacy, only anonymous data were extracted from the CDSS. Data could not be used to identify individual patients or pharmacies.

\section{Results}

The 351 participating pharmacies dispensed 749,659 prescriptions of the seven investigated antibiotics and they registered the management of 88,391 alerts. Incomplete data recording (see Table 1) was found in $15.4 \%$ of the records ( $n=13,607)$; it was almost entirely caused by lack of registration of the eGFR. The data consistency check showed inconsistent registration in $4.1 \%$ of the records $(n=3654)$.

The 88,391 alerts were generated for 64,763 patients. Most alerts were generated for prescriptions of nitrofurantoin $(43,417$ alerts, $49.1 \%)$, followed by amoxicillin + clavulanic acid $(16,994$ alerts, $19.2 \%)$ and ciprofloxacin (11,519 alerts, $13.0 \%)$; see Table 2 . The majority of the alerts were generated for patients aged $70-79$ years $(42,126$ alerts, $47.7 \%)$ and patients aged $80-89$ years $(35,168$ alerts, $39.8 \%)$. The very elderlyaged 90 years and over-accounted for $11.7 \%$ of the alerts ( $n=10,306$ ); only $0.9 \%$ of the alerts were generated for patients under 70 years of age $(n=791)$. 
Table 1 Check of consistency and completeness of data registration

\begin{tabular}{|c|c|c|c|c|}
\hline \multirow{2}{*}{$\begin{array}{l}\text { Examples of check on } \\
\text { consistency and } \\
\text { completeness of data } \\
\text { registration }\end{array}$} & \multicolumn{2}{|c|}{ Registered alert management } & \multirow{2}{*}{$\begin{array}{l}{[\mathrm{III}] \text { Registered }} \\
\text { renal function }\end{array}$} & \multirow{2}{*}{$\begin{array}{l}\text { [IV] Corresponding record in medication dispensing } \\
\text { history (based on ATC of the medication for which } \\
\text { the alert had been generated) }\end{array}$} \\
\hline & [I] Situation & $\begin{array}{l}{[\mathrm{II}]} \\
\text { Intervention }\end{array}$ & & \\
\hline $\begin{array}{l}\text { Example 1: consistent and } \\
\text { complete }\end{array}$ & $\begin{array}{l}\text { Renal function is } \\
\text { below threshold } \\
\text { and dose is too } \\
\text { high }\end{array}$ & $\begin{array}{l}\text { Dose } \\
\text { adjustment }\end{array}$ & $\begin{array}{l}\text { eGFR } \leq 30 \mathrm{ml} / \\
\mathrm{min} / 1.73 \mathrm{~m}^{2} \\
(\leq 56 \text { weeks } \\
\text { ago })\end{array}$ & $\begin{array}{l}\text { Medication record with reduced dose (appropriate } \\
\text { for renal impairment) }\end{array}$ \\
\hline $\begin{array}{l}\text { Example 2: consistent and } \\
\text { complete }\end{array}$ & $\begin{array}{l}\text { Renal function } \\
\text { unknown; } \\
\text { dispensed }\end{array}$ & $\begin{array}{l}\text { No } \\
\text { intervention }\end{array}$ & $\begin{array}{l}\text { No registered } \\
\text { renal function }\end{array}$ & Medication record with normal dose \\
\hline $\begin{array}{l}\text { Example 3: inconsistent (on } \\
\text { item IV) }\end{array}$ & $\begin{array}{l}\text { Renal function is } \\
\text { below threshold } \\
\text { and dose is too } \\
\text { high }\end{array}$ & $\begin{array}{l}\text { Dose } \\
\text { adjustment }\end{array}$ & $\begin{array}{l}\text { eGFR } \leq 30 \mathrm{ml} / \\
\mathrm{min} / 1.73 \mathrm{~m}^{2} \\
(\leq 56 \text { weeks } \\
\text { ago })\end{array}$ & Medication record with normal dose \\
\hline $\begin{array}{l}\text { Example 4: inconsistent (on } \\
\text { item III) }\end{array}$ & $\begin{array}{l}\text { Renal function is } \\
\text { above threshold }\end{array}$ & $\begin{array}{l}\text { No } \\
\text { intervention }\end{array}$ & $\begin{array}{l}\text { eGFR } \leq 30 \mathrm{ml} / \\
\mathrm{min} / 1.73 \mathrm{~m}^{2} \\
(>56 \text { weeks } \\
\text { ago })\end{array}$ & Medication record with normal dose \\
\hline $\begin{array}{l}\text { Example 5: incomplete (on } \\
\text { item III) }\end{array}$ & $\begin{array}{l}\text { Renal function is } \\
\text { below threshold } \\
\text { and dose is too } \\
\text { high }\end{array}$ & $\begin{array}{l}\text { Dose } \\
\text { adjustment }\end{array}$ & $\begin{array}{l}\text { No registered } \\
\text { renal function }\end{array}$ & $\begin{array}{l}\text { Medication record with reduced dose (appropriate } \\
\text { for renal impairment) }\end{array}$ \\
\hline
\end{tabular}

$A T C$ anatomical therapeutic chemical classification [25], eGFR estimated glomerular filtration rate

For $93.3 \%$ of the 88,391 alerts, the data recording showed that they were generated because information on renal function was lacking or outdated. In $15.5 \%$ of the alerts, the pharmacist decided to dispense the prescribed drug without recent information on the renal function of the patient (Table 2). In $2.0 \%$ of the alerts, the pharmacist had patient information indicating a special situation, for example, that it concerned a patient on dialysis. For the other alerts $(82.5 \%)$, the pharmacist obtained or already had information on the patient's renal function. This information led to unchanged dispensing in the majority of cases, most often because the eGFR was above the threshold of $30 \mathrm{ml} / \mathrm{min} / 1.73 \mathrm{~m}^{2}$ (77.7\% of the alerts). In addition, in $3.0 \%$ of the cases $(n=2631)$, the pharmacist judged that no intervention was needed although the eGFR was below $30 \mathrm{ml} / \mathrm{min} / 1.73 \mathrm{~m}^{2}$, for example, because the prescribed dose was appropriate for this renal function. In $1.4 \%$ of the alerts, the prescribed dose was adjusted after intervention by the pharmacist, and in $0.4 \%$ of the alerts the drug was replaced. So, the management of alerts led overall to 1532 prescription modifications $(1.7 \%)$ because of renal impairment. Within the patient group with severe renal impairment (eGFR of $\left.\leq 30 \mathrm{ml} / \mathrm{min} / 1.73 \mathrm{~m}^{2}\right)(n=4163)$, the intervention rate was $36.8 \%$ (1532 cases with intervention). Patients aged 90 and over accounted for $24.7 \%$ of the prescription modifications $(n=378)$.

In 1988 cases ( $2.2 \%$ of the alerts), the pharmacist performed a PoCT to obtain information on the renal function before dispensing the antibiotic. In 1852 of the PoCTs, the
eGFR was documented in the CDSS. In 170 of these cases (9.2\%), the eGFR obtained by PoCT was $\leq 50 \mathrm{ml} / \mathrm{min} /$ $1.73 \mathrm{~m}^{2}$, of which 18 cases $(1.0 \%)$ had an eGFR of $\leq 30 \mathrm{ml} / \mathrm{min} / 1.73 \mathrm{~m}^{2}$. The PoCT measurements resulted in 15 prescription modifications $(0.8 \%$ of the PoCT). In three cases, nitrofurantoin was replaced by another antibiotic. In 12 cases, the dose of the antibiotic was reduced.

The percentage of PoCT with an eGFR of $\leq 50 \mathrm{ml} / \mathrm{min} /$ $1.73 \mathrm{~m}^{2}$ was $6.1 \%$ for patients under 80 years of age, $11.6 \%$ for patients $80-89$ years-old, and $29.2 \%$ for patients 90 years of age and older.

At the end of the study period, 49,178 of the 64,763 patients $(75.9 \%)$ had a renal function registered in the CDSS. For 13,252 $(26.9 \%)$ of the patients with a documented renal function, at least one eGFR of $\leq 50 \mathrm{ml} / \mathrm{min} /$ $1.73 \mathrm{~m}^{2}$ had been registered. For 2144 patients $(4.4 \%)$, at least one eGFR of $\leq 30 \mathrm{ml} / \mathrm{min} / 1.73 \mathrm{~m}^{2}$ had been registered.

\section{Discussion}

The 351 participating pharmacists managed nearly 90,000 alerts on antibiotics and impaired renal function in 15 months. This led to over 1500 prescription modifications and nearly 2000 PoCTs. However, for patients with an impaired renal function (eGFR of $\leq 30 \mathrm{ml} / \mathrm{min} /$ $1.73 \mathrm{~m}^{2}$ ), we observed a much higher intervention rate of 


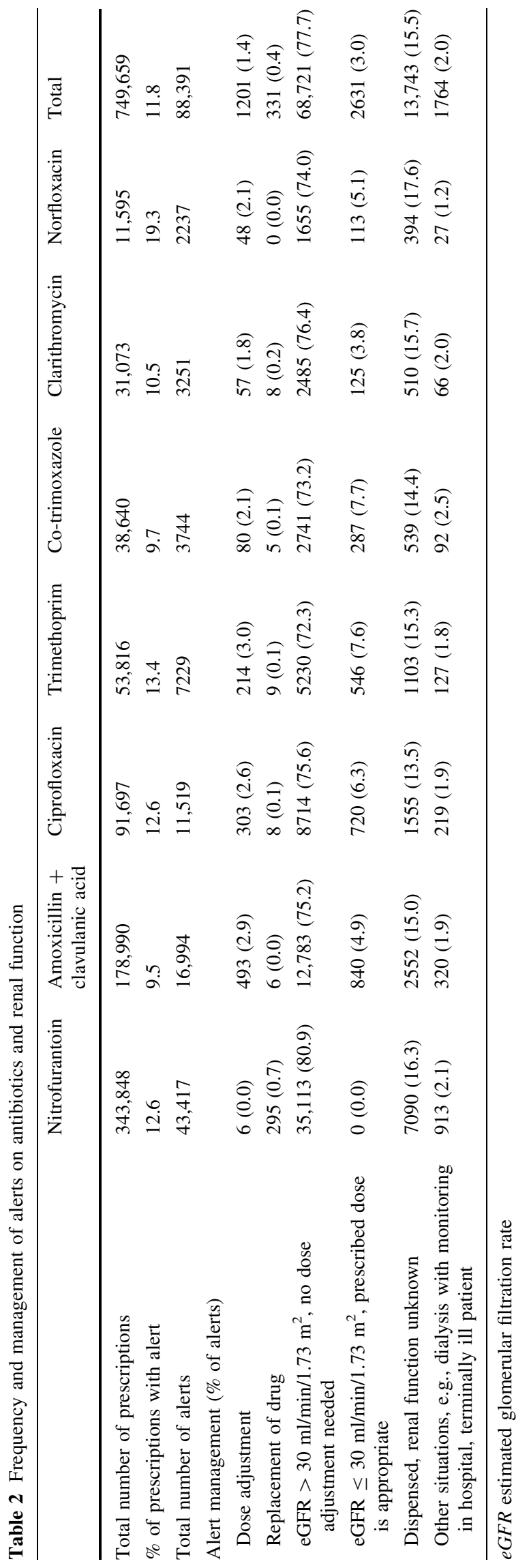

$36.8 \%$. Low intervention rates $(<10 \%)$ are not uncommon in routinely used CDSSs [27-30]. The low overall intervention rate in our study was specifically caused by triggering of alerts by missing information on renal function (over $90 \%$ of the alerts).

Better exchange and registration of the available information on renal function would have reduced the number of unnecessary CDSS alerts in our study, thereby increasing the percentage of relevant alerts. This is caused by the fact that in $78 \%$ of the alerts in our investigation, the information on renal function retrieved by the pharmacists showed an eGFR of $>30 \mathrm{ml} / \mathrm{min} / 1.73 \mathrm{~m}^{2}$. If the renal function had been available in the CDSS beforehand, no alert would have appeared. So, the main reason for alert generation in our study was the high number of missing or outdated eGFR values in the CDSS. Furthermore, in 3\% of the alerts, the renal function was impaired, but the dose of the antibiotic had already been adjusted. Probably, the prescriber was aware of the impaired renal function and wrote the prescription according to the dosing guidelines. These alerts would not appear in an improved, more specific CDSS with automatic consideration of the actual dose in relation to the reference dose (taking into account the indication), a function that was missing in the investigated CDSS. So, combining better registration of renal function in the CDSS and extended CDSS functionality would have reduced the number of alerts by $81 \%$.

The total number of 1988 performed PoCTs was relatively low, which indicates that in most cases pharmacists were well able to retrieve information on renal function from other sources, for example, the prescriber (or that the pharmacist judged that dispensing without information on renal function was acceptable). In $0.8 \%$ of the PoCTs, the prescription was modified, which was less than the overall result of $1.7 \%$ prescription modifications. This can be explained by the fact that for patients with risk factors for renal impairment (for example, diabetes), it is more likely that information on renal function was already available. In 9\% of the PoCTs, an impaired renal function was found. This indicates that the 'number needed to test' to identify one patient with an eGFR of $\leq 50 \mathrm{ml} / \mathrm{min} / 1.73 \mathrm{~m}^{2}$ was 11 . In patients aged 90 years and over, the 'number needed to test' to identify one patient with an eGFR of $\leq 50 \mathrm{ml} / \mathrm{min} /$ $1.73 \mathrm{~m}^{2}$ was only 3 . Based on these results, performing PoCT is probably the most worthwhile in the patient groups with the highest age; further research is needed to better specify in which patient groups PoCT should be used for the optimal balance between efficiency and safety.

More in general, PoCT is useful when information on renal function is urgently needed, when the intended drug needs dose adjustment or replacement even in the case of mild or moderate impaired renal function, and when the prescribed drug has a narrow therapeutic window. The 
antibiotics included in this investigation needed dose adjustment in the case of severely impaired renal function (eGFR of $\leq 30 \mathrm{ml} / \mathrm{min} / 1.73 \mathrm{~m}^{2}$ ). This explains the limited number of prescription modifications after PoCT. Although at the time of the POCT no intervention may have been needed, the retrieved (impaired) renal function can be useful for assessment of other prescriptions in the near future. The identification of patients with a severely impaired renal function can especially be relevant when the patient has not been diagnosed with renal impairment before. Although PoCT for creatinine is not completely equivalent to laboratory measurement, it has been shown to be sufficiently accurate for detecting relevantly impaired renal function [22].

By the end of the study period, a renal function was registered for about $75 \%$ of the patients. This percentage is in the upper range of results from some recent surveys about the availability of information on renal function in community pharmacy [16, 17]. This suggests that the routine use of the CDSS can contribute to better documentation of renal function. In about $15 \%$ of the alerts, the antibiotic was dispensed while the pharmacist had no information on the patient's renal function. The reasons can be several; for example, no information on renal function was available over the last year, but 18 months ago the renal function was normal. When the patient has a stable health condition, the pharmacist probably judged it very unlikely that the current eGFR was under $30 \mathrm{ml} / \mathrm{min} /$ $1.73 \mathrm{~m}^{2}$ (the threshold for intervention for the antibiotics in this investigation).

The CDSS generated alerts based on the most recent registered renal function. A measurement of up to 13 months ago (56 weeks) was considered recent-consistent with yearly monitoring. Renal function can, however, fluctuate over time, especially in patients with an unstable condition (for example, after hospital admission) [31]. Single point measurements therefore have limited validity, and after finding potentially impaired renal function, repeated measurements are needed. Moreover, the eGFR can be an underestimation or overestimation of the actual value. Formulas for estimating GFR should be applied carefully, and the patients' individual characteristics should be taken into account $[32,33]$. Future CDSSs could be improved by incorporating historical trends in patients' renal function and patient characteristics affecting GFR estimates in the algorithms. But even then clinical decision support is only a tool to detect a potential problem. The management of an alert needs an individualized assessment by a competent health care professional.

This retrospective observational study has strengths and limitations. A major strength is the large sample size: the management of nearly 90,000 alerts was investigated and the CDSS and PoCT were used in over 350 pharmacies.
Therefore, our study gives an overview of routine alert management by community pharmacists. Moreover, it shows that a CDSS can be successfully implemented on a large scale in daily community pharmacy practice, as our study included one sixth of all community pharmacies in the Netherlands.

A first limitation is that the appropriateness of the alert management and the renal function estimation by the pharmacists for the concerned patients was not assessed by the researchers (e.g., whether dispensing without knowing the renal function was acceptable). The estimation and interpretation of the renal function and the relevance of the intervention are dependent on individual patient characteristics. Future research could elucidate pharmacists' assessment of CDSS alerts regarding renal function.

Secondly, because of the routine registration in daily practice and the large number of participating pharmacists, incorrect registrations might have occurred. To reduce variation, all pharmacists were trained on correct registration of alert management. We checked data consistency and rated it as acceptable for a large scale observational study in daily practice, with less than 5\% inconsistent registrations. Data completeness was good, except for registration of the value of eGFR, which was missing in about $15 \%$ of the records. However, because information on eGFR category $\left(\leq\right.$ or $\left.>30 \mathrm{ml} / \mathrm{min} / 1.73 \mathrm{~m}^{2}\right)$ was available for the records concerned, it is unlikely that study results were relevantly affected.

Insight in the current management of drug therapy alerts on renal impairment can contribute to better CDSSs and to better alert management by the health care professional. In future research, a focus on the interpretation of renal function measures on the level of the individual patient, supported by CDSSs, could complement the current knowledge in this field.

\section{Conclusion}

Community pharmacists performed CDSS-based interventions to prevent potentially inappropriate (dosing of) antibiotics in elderly patients with renal impairment. Pharmacists retrieved most data on renal function from other health care professionals, and they used PoCT only in a limited number of cases. The intervention rate could be greatly increased by better registration of information on renal function to automatically identify the patients with impaired renal function. Performing PoCT seems especially worthwhile in the highest age groups.

Acknowledgements We thank P. Hoogland from Service Apotheek, a Dutch community pharmacy franchise organization, and M. Spies from NControl, the associated data warehouse, for provision of the 
data. We thank B. Rostai (Utrecht University) for his valuable comments.

Author Contributions All authors contributed to the study design, the data interpretation and the manuscript. MH performed the data analysis and drafted the manuscript. All authors approved the final manuscript.

\section{Compliance with Ethical Standards}

Conflict of interest The authors have no conflicts of interest that are directly relevant to the content of this study.

Funding The authors received for this study no specific grant from any funding agency in the public, commercial or not-for-profit sectors. The study data were derived from community pharmacies that were franchisees of Service Apotheek. Data were provided free of charge by the associated data warehouse NControl.

Ethics and confidentiality As this was a retrospective anonymized database analysis, the study was exempt from ethical review. To protect patients' and pharmacists' privacy, only anonymous data were extracted from the clinical decision support system. Data could not be used to identify individual patients or pharmacies.

Open Access This article is distributed under the terms of the Creative Commons Attribution-NonCommercial 4.0 International License (http://creativecommons.org/licenses/by-nc/4.0/), which permits any noncommercial use, distribution, and reproduction in any medium, provided you give appropriate credit to the original author(s) and the source, provide a link to the Creative Commons license, and indicate if changes were made.

\section{References}

1. Mills KT, Xu Y, Zhang W, et al. A systematic analysis of worldwide population-based data on the global burden of chronic kidney disease in 2010. Kidney Int. 2015;88:950-7. https://doi. org/10.1038/ki.2015.230.

2. Zhang QL, Rothenbacher D. Prevalence of chronic kidney disease in population-based studies: systematic review. BMC Public Health. 2008;8:117. https://doi.org/10.1186/1471-2458-8-117.

3. De Nicola L, Zoccali C. Chronic kidney disease prevalence in the general population: heterogeneity and concerns. Nephrol Dial Transplant. 2016;31:331-5. https://doi.org/10.1093/ndt/gfv427.

4. Leendertse AJ, Van Dijk AE, De Smet PAGM, et al. Contribution of renal impairment to potentially preventable medication-related hospital admissions. Ann Pharmacother. 2012;46:625-33. https:// doi.org/10.1345/aph.1Q633.

5. Leendertse A, Egberts A, Stoker L, et al. Frequency of and risk factors for preventable medication-related hospital admissions in the Netherlands. Arch Intern Med. 2008;168:1890-6.

6. Oplinger $\mathrm{M}$, Andrews $\mathrm{CO}$. Nitrofurantoin contraindication in patients with a creatinine clearance below $60 \mathrm{~mL} / \mathrm{min}$ : looking for the evidence. Ann Pharmacother. 2013;47:106-11. https://doi. org/10.1345/aph.1R352.

7. Curtain C, Peterson GM. Review of computerized clinical decision support in community pharmacy. J Clin Pharm Ther. 2014;39:343-8. https://doi.org/10.1111/jcpt.12168.

8. Bright TJ, Wong A, Dhurjati R, et al. Effect of clinical decisionsupport systems: a systematic review. Ann Intern Med. 2012;157:29-43. https://doi.org/10.1059/0003-4819-157-1201207030-00450.
9. Bayoumi I, Al Balas M, Handler SM, et al. The effectiveness of computerized drug-lab alerts: a systematic review and metaanalysis. Int J Med Inform. 2014;83:406-15. https://doi.org/10. 1016/j.ijmedinf.2014.03.003.

10. Seidling HM, Schmitt SP, Bruckner T, et al. Patient-specific electronic decision support reduces prescription of excessive doses. Qual Saf Health Care. 2010;19:e15. https://doi.org/10. 1136/qshc.2009.033175.

11. Awdishu L, Coates CR, Lyddane A, et al. The impact of real-time alerting on appropriate prescribing in kidney disease: a cluster randomized controlled trial. J Am Med Inform Assoc. 2016;23:609-16. https://doi.org/10.1093/jamia/ocv159.

12. Nanji KC, Slight SP, Seger DL, et al. Overrides of medicationrelated clinical decision support alerts in outpatients. J Am Med Inform Assoc. 2014;21:487-91. https://doi.org/10.1136/amiajnl2013-001813.

13. Via-Sosa MA, Lopes N, March M. Effectiveness of a drug dosing service provided by community pharmacists in polymedicated elderly patients with renal impairment-a comparative study. BMC Fam Pract. 2013;14:96. https://doi.org/10.1186/1471-229614-96.

14. Joosten H, Drion I, Boogerd KJ, et al. Optimising drug prescribing and dispensing in subjects at risk for drug errors due to renal impairment: improving drug safety in primary healthcare by low eGFR alerts. BMJ Open. 2013;3:e002068. https://doi.org/10. 1136/bmjopen-2012-002068.

15. Pourrat X, Sipert AS, Gatault P, et al. Community pharmacist intervention in patients with renal impairment. Int J Clin Pharm. 2015;37:1172-9. https://doi.org/10.1007/s11096-015-0182-4.

16. Smits E, Houben E, de Smet PAGM, et al. The availability of information on impaired renal function in the community pharmacy, a descriptive pilot study. HSOA J Nephrol Renal Ther. 2016;2:003.

17. Koster ES, Philbert D, Noordam M, et al. Availability of information on renal function in Dutch community pharmacies. Int $\mathbf{J}$ Clin Pharm. 2016;38:797-801. https://doi.org/10.1007/s11096016-0332-3.

18. Floor-Schreudering A, Heringa M, Buurma H, et al. Missed drug therapy alerts as a consequence of incomplete electronic patient records in Dutch community pharmacies. Ann Pharmacother. 2013;47:1272-9. https://doi.org/10.1177/1060028013501992.

19. Geerts AF, De Koning FH, De Vooght KM, et al. Feasibility of point-of-care creatinine testing in community pharmacy to monitor drug therapy in ambulatory elderly patients. J Clin Pharm Ther. 2013;38:416-22. https://doi.org/10.1111/jcpt.12081.

20. Royal Dutch Pharmacists Association (KNMP). Zakboek Verminderde Nierfunctie (Dutch guidelines for drug-dosing in chronic kidney disease). The Hague, The Netherlands 2012.

21. Vidal L, Shavit M, Fraser A, et al. Systematic comparison of four sources of drug information regarding adjustment of dose for renal function. BMJ. 2005;331:263. https://doi.org/10.1136/bmj. 38476.471088.3A.

22. Kosack CS, de Kieviet W, Bayrak K, et al. Evaluation of the Nova StatSensor(R) Xpress(TM) creatinine point-of-care handheld analyzer. PLoS One. 2015;10:e0122433. https://doi.org/10. 1371/journal.pone.0122433.

23. Levey AS, Greene T, Kusek JW, et al. A simplified equation to predict glomerular filtration rate from serum creatinine. J Am Soc Nephrol. 2000;11:155a.

24. Cockcroft DW, Gault MH. Prediction of creatinine clearance from serum creatinine. Nephron. 1976;16:31-41.

25. ATC/DDD Index. 2016. http://www.whocc.no/atc_ddd_index. Accessed Aug 2016.

26. Committee for Medicinal Products for Human Use (CHMP). Note for guidance on the evaluation of the pharmacokinetics of medicinal products in patients with impaired renal function 2004; 
CHMP/EWP/225/02. European Medicines Agency, London, United Kingdom.

27. Bryant AD, Fletcher GS, Payne TH. Drug interaction alert override rates in the meaningful use era: no evidence of progress. Appl Clin Inform. 2014;5:802-13. https://doi.org/10.4338/ACI2013-12-RA-0103.

28. Eppenga WL, Derijks HJ, Conemans JM, et al. Comparison of a basic and an advanced pharmacotherapy-related clinical decision support system in a hospital care setting in the Netherlands. J Am Med Inform Assoc. 2012;19:66-71. https://doi.org/10.1136/ amiajnl-2011-000360.

29. Buurma H, De Smet PAGM, Egberts AC. Clinical risk management in Dutch community pharmacies: the case of drug-drug interactions. Drug Saf. 2006;29:723-32. https://doi.org/10.2165/ 00002018-200629080-00009.

30. van der Sijs H, Aarts J, Vulto A, et al. Overriding of drug safety alerts in computerized physician order entry. J Am Med Inform Assoc. 2006;13:138-47. https://doi.org/10.1197/jamia.M1809.
31. Eppenga WL, Wester WN, Derijks HJ, et al. Fluctuation of the renal function after discharge from hospital and its effects on drug dosing in elderly patients-study protocol. BMC Nephrol. 2015;16:95. https://doi.org/10.1186/s12882-015-0095-4.

32. Eppenga WL, Kramers C, Derijks HJ, et al. Drug therapy management in patients with renal impairment: how to use creatininebased formulas in clinical practice. Eur J Clin Pharmacol. 2016;72:1433-9. https://doi.org/10.1007/s00228-016-2113-2.

33. Eppenga WL, Kramers C, Derijks HJ, et al. Individualizing pharmacotherapy in patients with renal impairment: the validity of the modification of diet in renal disease formula in specific patient populations with a glomerular filtration rate below $60 \mathrm{ml} /$ min. A systematic review. PLoS One. 2015;10:e0116403. https:// doi.org/10.1371/journal.pone.0116403. 